\title{
ДЕФИЦИТ МЕСТНОГО БЮДЖЕТА И МУНИЦИПАЛЬНЫЙ ДОЛГ
}

\section{(C) 2019 Сугарова Ирина Валерьевна}

доктор экономических наук, профессор кафедры «Финансы и кредит» Северо-Осетинский государственный университет имени К.Л. Хетагурова, Россия, Владикавказ

E-mail: sugaririna@yandex.ru

\section{(c) 2019 Тадтаева Наира Валерьевна}

ассистент кафедры «Финансы и кредит»

Северо-Осетинский государственный университет имени К.Л. Хетагурова, Россия, Владикавказ

E-mail: nairatad@yandex.ru

В современных экономических условиях проблематика государственного и муниципального долгов находится в числе приоритетных. Безусловно, она разносторонне исследовалась в трудах различных ученых - экономистов. Вместе с тем, дальнейшее исследование вопросов образования дефицита бюджета и бюджетных долгов является актуальным и востребованным.

Ключевые слова: местные бюджеты, доходы бюджета, расходы бюджета, дефицит бюджета, муниципальный долг, структура долга, бюджетные кредиты.

Проблематика муниципального долга занимает особое место среди вопросов современной бюджетной политики. Это объясняется постоянным ростом долговых обязательств муниципалитетов, вызванных значительным сокращением доходной базы местных бюджетов.

Получая все большую автономию и законодательно предоставляемую самостоятельность, местные органы власти сталкиваются с систематическим непокрытием бюджетных потребностей собственными доходами и с возрастающей зависимостью от различных форм дотационной помощи и поддержки бюджетами других уровней единой бюджетной системы. Тем самым для муниципальных органов власти возникают постоянно формирующиеся проблемы выбора наиболее приемлемых возможностей решения бюджетных задач (таблица 1 ).
Финансовые проблемы местного самоуправления не исчерпываются общим недостатком финансовых ресурсов, обусловленным отчасти, как нами отмечалось, вертикальной несбалансированностью (чрезмерной централизацией) бюджетной системы, отчасти слабой активностью местных властей в проведении реформ. Не менее серьезная проблема - структурное несоответствие муниципальных доходов и расходов. Первый аспект такого несоответствия заключается в том, что в структуре муниципальных доходов наблюдается явный перекос в пользу средств бюджетного регулирования, на долю которых приходится около 50\% средств местного самоуправления.

Такая практика в определенной степени подсказывает относительно низкий уровень бюджетного интереса многих регионов к развитию

Таблица 1. Исполнение местных бюджетов Российской Федерации за 2016-2018 годы

\begin{tabular}{|l|c|c|c|}
\hline \multicolumn{1}{|c|}{ Показатель } & $\begin{array}{c}\text { Исполнено за 2016 год, } \\
\text { млрд. руб. }\end{array}$ & $\begin{array}{c}\text { Исполнено за 2017 год, } \\
\text { млрд. руб. }\end{array}$ & $\begin{array}{c}\text { Исполнено за 2018 год, } \\
\text { млрд. руб. }\end{array}$ \\
\hline Доходы, всего & 3645,1 & 3845,7 & 4245,7 \\
\hline Собственные доходы & 2352,0 & 2504,8 & 2791,2 \\
\hline Налоговые доходы & 1053,6 & 1122,9 & 268,7 \\
\hline Неналоговые доходы & 277,5 & 269,9 & 1291,1 \\
\hline $\begin{array}{l}\text { Межбюджетные трансферты } \\
\text { из бюджетов других уровней } \\
\text { (без субвенций) }\end{array}$ & 1020,9 & 1112,0 & 4226,9 \\
\hline Расходы, всего & 3655,1 & 3882,2 & 18,8 \\
\hline Дефицит/Профицит & $-10,0$ & $-36,5$ & \\
\hline
\end{tabular}


экономического потенциала местных территорий и созданию дополнительных условий для наращивания их бюджетных доходов, и соответственно, на расширение и собираемость налогов.

Чем больше проблем формирующихся доходов местных бюджетов, тем острее и масштабнее возникают задачи в обосновании и регулировании фактического осуществления их расходов.

Для правильной оценки этого процесса нужно учитывать, что российские муниципальные образования заметно различаются как по уровню фактических налоговых доходов, так и по налоговому потенциалу.

В такой динамике показателей доходов и расходов местных бюджетов, как нами оценивается, формируется определенный круг проблем, прежде всего, связанных с отсутствием бюджетной сбалансированностью в рамках муниципалитетов и формировании на этом фоне территориальной бюджетной неравномерности.

При этом считаем, что понятие сбалансированности многогранно и для его достижения требуется соответствующий механизм, обеспечивающий наращивание доходной базы бюджетов и целевому и эффективному расходованию бюджетных средств.

Считаем важным, что основные задачи оптимизации бюджетных расходов связаны с:

- анализом эффективности расходов на предоставление бюджетных услуг;

- анализом эффективности социальных выплат и льгот;

- ограничением принятия новых расходных обязательств, не увеличение финансирования действующих расходных обязательств;

- разработкой системы раннего предупреждения появления непредвиденных расходов (в том числе на основе контроля за финансовым состоянием предприятий и организаций, находящихся в собственности муниципальных образований);

- установлением размера дефицита бюджета с учетом снижения доступности кредитных ресурсов и возможности размещения муниципальных ценных бумаг.

Следует отметить, что долги бюджетов образуются на основе их дефицитности, а причиной ее образования, как правило, является несбалансированность доходов и расходов.

С теоретической точки зрения важно также подчеркнуть, что дефицит бюджета - превы- шение расходов над доходами. Это необходимо расценивать как финансовое явление и как финансовую проблему для любого бюджета. В основе своей, и это бесспорно, бюджетный дефицит нежелателен в бюджетной практике, как бы он не покрывался. Однако, давая оценку дефициту бюджета как финансовому явлению или как финансовой проблеме необходимо исследовать качество и причины возникновения. И этому есть ряд обоснований.

Во-первых, дефицит бюджета может быть связан с необходимостью осуществления значительных государственных вливаний в развитие экономики, и в этом случае в его основе желание государства обеспечить развитие в структуре общественного воспроизводства;

Во-вторых, дефицит бюджета может возникнуть в результате непредвиденных чрезвычайных обстоятельств (природные катаклизмы, войны);

B-третьих, дефицит бюджета возникает в результате кризисных явлений в экономике, ведущих к ее развалу. Данная форма проявления бюджетного дефицита считается наиболее опасной и требующей принятия экстренных и эффективных экономических и политических решений.

Отметим, что бюджетное законодательство предполагает, что в случае принятия бюджета на очередной финансовый год с дефицитом законом (решением) об этом бюджете утверждаются источники финансирования дефицита бюджета (таблица 2).

В 2017 году общий объем расходов местных бюджетов превысил объем доходов местных бюджетов на 36,5 млрд. рублей (в 2016 году расходы местных бюджетов превысили доходы на 10,0 млрд. рублей). При этом в 25 субъектах Российской Федерации местные бюджеты исполнены с профицитом, который составил 9,0 млрд. рублей, в 60 субъектах Российской Федерации с дефицитом в сумме 45,5 млрд. рублей.

Субъекты Российской Федерации, имеющие наибольший профицит местных бюджетов по состоянию на 01.01.2018 (млрд. рублей):

- Свердловская область 1,9

- Московская область 1,2

- Алтайский край 0,9

- Тюменская область 0,8

- Республика Саха (Якутия) 0,6.

Субъекты Российской Федерации, имеющие 
Таблица 2. Источники финансирования дефицита бюджетов

\begin{tabular}{|c|c|c|}
\hline Федеральный бюджет & Бюджет субъекта РФ & Местный бюджет \\
\hline \multicolumn{3}{|c|}{ Источники внутреннего финансирования } \\
\hline \multicolumn{3}{|c|}{$\begin{array}{l}\text { разница между средствами, поступившими от размещения ценных бумаг, номинальная стоимость которых } \\
\text { указана в валюте Российской Федерации, и средствами, направленными на их погашение }\end{array}$} \\
\hline \multicolumn{3}{|c|}{$\begin{array}{l}\text { разница между полученными и погашенными в валюте Российской Федерации бюджетными кредитами, } \\
\text { предоставленными другими бюджетами бюджетной системы Российской Федерации }\end{array}$} \\
\hline \multicolumn{3}{|c|}{$\begin{array}{l}\text { разница между полученными и погашенными в валюте Российской Федерации кредитами кредитных орга- } \\
\text { низаций }\end{array}$} \\
\hline \multicolumn{3}{|c|}{$\begin{array}{l}\text { изменение остатков средств на счетах по учету средств бюджета в течение соответствующего финансового } \\
\text { года }\end{array}$} \\
\hline \multicolumn{2}{|c|}{$\begin{array}{l}\text { разница между полученными и погашенными в валюте Российской Федерации } \\
\text { кредитами международных финансовых организаций }\end{array}$} & - \\
\hline - & \multicolumn{2}{|c|}{$\begin{array}{l}\text { разница между полученными и погашенными в } \\
\text { иностранной валюте бюджетными кредитами, пре- } \\
\text { доставленными Российской Федерацией в рамках } \\
\text { использования целевых иностранных кредитов } \\
\text { (заимствований) }\end{array}$} \\
\hline \multicolumn{3}{|l|}{ иные источники внутреннего финансирования } \\
\hline \multicolumn{3}{|c|}{ Источники внешнего финансирования } \\
\hline \multicolumn{2}{|c|}{$\begin{array}{l}\text { разница между средствами, поступившими от размещения государственных } \\
\text { займов, которые осуществляются путем выпуска государственных ценных бумаг, } \\
\text { и номинальная стоимость которых указана в иностранной валюте, и средствами, } \\
\text { направленными на их погашение }\end{array}$} & - \\
\hline \multicolumn{2}{|c|}{$\begin{array}{l}\text { разница между полученными и погашенными в иностранной валюте кредитами } \\
\text { кредитных организаций }\end{array}$} & - \\
\hline $\begin{array}{l}\text { разница между полученными и погашенными в ино- } \\
\text { странной валюте кредитами иностранных государств, } \\
\text { включая целевые иностранные кредиты (заимствова- } \\
\text { ния), с учетом средств, перечисленных из федерально- } \\
\text { го бюджета российским поставщикам товаров и (или) } \\
\text { услуг на экспорт в счет погашения государственного } \\
\text { внешнего долга РФ, международных финансовых } \\
\text { организаций, иных субъектов международного права } \\
\text { и иностранных юридических лиц }\end{array}$ & - & - \\
\hline \multicolumn{2}{|l|}{ иные источники внешнего финансирования } & - \\
\hline
\end{tabular}

Составлена авторами на основе Бюджетного кодекса РФ.

наибольший дефицит местных бюджетов по состоянию на 01.01.2018 (млрд. рублей):

- Нижегородская область $-4,0$

- Новосибирская область $-3,3$

- Сахалинская область -3,1

- Самарская область $-2,6$

- Амурская область $-2,4$

В 2018 году общий объем доходов местных бюджетов превысил объем расходов местных бюджетов на 18,8 млрд. рублей (в 2017 году расходы местных бюджетов превысили доходы на 36,5 млрд. рублей). При этом в 40 субъектах Российской Федерации местные бюджеты исполнены с профицитом, который составил 35,6 млрд. рублей, в 45 субъектах Российской Федерации с дефицитом в сумме 16,8 млрд. рублей.

Субъекты Российской Федерации, имеющие наибольший профицит местных бюджетов по состоянию на 01.01.2019 (млрд. рублей):

- Ханты-Мансийский автономный округ 4,6

- Пермский край 3,8

- Тюменская область 3,2

- Калужская область 2,9

- Республика Саха (Якутия) 2,3.

Субъекты Российской Федерации, имеющие наибольший дефицит местных бюджетов по состоянию на 01.01.2019 (млрд. рублей):

- Московская область $-2,8$

- Сахалинская область $-1,1$

- Ярославская область -0,9

- Волгоградская область -0,8

- Тульская область $-0,7$.

На фоне роста бюджетной несбалансированности происходит увеличение долговых обязательств муниципальных образований.

Рассматривая муниципальный долг как ком- 
плексную категорию, считаем необходимым, выделить его содержательные характеристики:

- муниципальный долг, как экономическая категория, представляет собой экономические отношения, возникающие между муниципальным образованием с одной стороны и юридическими или физическими лицами, с другой стороны, при которых муниципалитет выступает в роли заёмщика денежных средств. Как экономическая категория, муниципальный долг представляет собой механизм привлечения денежных ресурсов для покрытия возникающего дефицита местного бюджета;

- муниципальный долг, являясь финансовой категорией, обладает способностью отражать рациональность и эффективность использования финансовых ресурсов муниципального образования;

- муниципальный долг, будучи институт финансового права, рассматривается как совокупность юридических норм, регулирующих общественные отношения, которые складываются «в процессе исполнения обязательств, возникающих из муниципальных заимствований, гарантий по обязательствам третьих лиц, других обязательств в соответствии с видами долговых обязательств», установленных Бюджетным кодексом РФ, принятых на себя муниципальным образованием.
Динамика показателя муниципального долга по Российской Федерации представлена на рисунке 1.

Структура муниципального долга Российской Федерации представлена в таблице 3.

Согласно представленным на рисунке 3 данным, наибольший удельный вес в структуре муниципального долга Российской Федерации занимали кредиты кредитных организаций, причем данный показатель за анализируемый период имел тенденцию к росту: 2016 г. - 59,7\%, 2017 г. $-65,6 \%, 2018$ г.-69,0\%.

Вторым наиболее значимым источником в структуре муниципального долга являлись бюджетные кредиты.

Отметим, что бюджетный кредит, в соответствии с законодательством, подразумевает денежные средства, предоставляемые бюджетом другому бюджету бюджетной системы Российской Федерации, юридическому лицу (за исключением государственных (муниципальных) учреждений), иностранному государству, иностранному юридическому лицу на возвратной и возмездной основах.

Безусловно, предоставление бюджетного кредита связано с соблюдением ряда условий. Во - первых, предусматривает заключение договора в соответствии с гражданским законодательством РФ в пределах бюджетных ассиг-

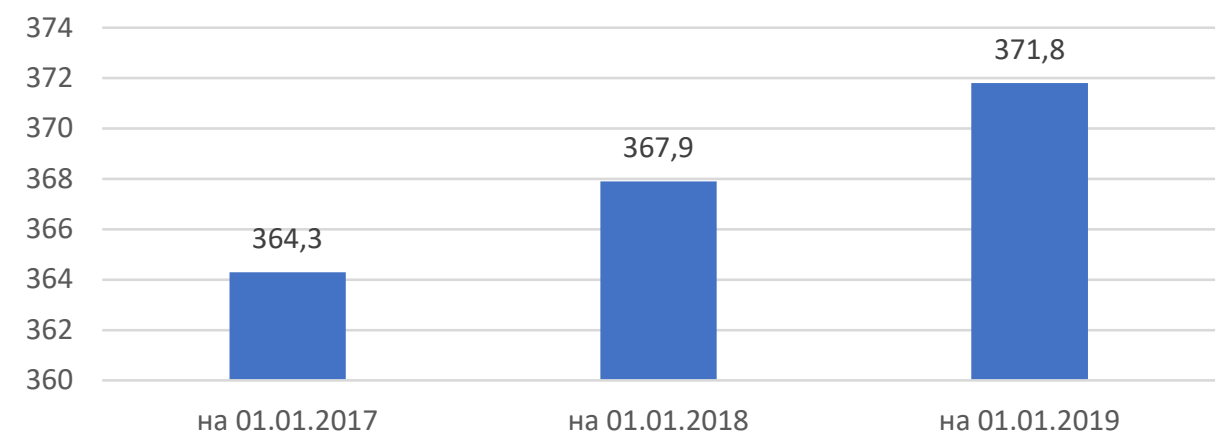

Рисунок 1. Динамика показателя муниципального долга по Российской Федерации

Таблица 3. Структура муниципального долга,\%

\begin{tabular}{|l|c|c|c|}
\hline \multicolumn{1}{|c|}{ Показатель } & 2016 г. & 2017 г. & 2018 г. \\
\hline Кредиты кредитных организаций & 59,7 & 65,6 & 69,0 \\
\hline $\begin{array}{l}\text { Бюджетные кредиты, привлекаемые из других } \\
\text { бюджетов бюджетной системы РФ }\end{array}$ & 30,4 & 24,6 & 23,3 \\
\hline Муниципальные гарантии & 6,9 & 4,1 & 2,9 \\
\hline Муниципальные ценные бумаги & 3,0 & 5,7 & 4,8 \\
\hline
\end{tabular}

Источник: Официальный сайт Министерства финансов РФ: http://www.minfin.ru 
нований, предусмотренных соответствующими законами (решениями) о бюджете.

Во-вторых, субъект Российской Федерации, муниципальное образование или юридическое лицо, не должно иметь просроченной задолженности по денежным обязательствам (обязательным платежам в бюджетную систему) перед соответствующим бюджетом (публичноправовым образованием), за исключением случаев реструктуризации обязательств (задолженности).

В-третьих, может быть предоставлен только при условии предоставление заемщиком обеспечения исполнения своего обязательства по возврату указанного кредита, уплате процентных и иных платежей, предусмотренных соответствующим договором (соглашением), за исключением случаев, когда заемщиком является Российская Федерация или субъект Российской Федерации.

На наш взгляд, допустим вывод о том, что одной из основополагающих закономерностей бюджетного процесса является снижение дефицитности бюджетов всех уровней единой бюджетной системы, с одновременным повышением эффективности расходования бюджетных средств. Есть и другая закономерность, и она состоит в том, что при прочих равных условиях роста доходов, которые имеют место в экономике, должны улучшаться возможности формирования бездефицитных бюджетов. Однако это получается далеко не всегда и причин бывает много. Например, есть экономическая и бюджетная проблематика структурированности доходов, Наиболее устойчивые поступления доходов в бюджеты идут от тех отраслей, которые являются материально производящими товарную продукцию.

Таким образом, для достижения эффективного управления муниципальным долгом, необходимо достижение таких целей как:

- отсутствие просроченных долговых обязательств муниципалитета;

- создание прозрачной системы управления;

- опубликование информации о долговой политике муниципалитета.

\section{Библиографический список}

1. Галазова С.С. Региональная экономика в системе национальной макроэкономики // Вестник РГГУ. Серия: Экономика. Управление. Право. 2015. № 3(146). С. 79-88.

2. Сугарова И.В. Совершенствование методов бюджетного планирования расходов//Вестник СевероОсетинского государственного университета имени Коста Левановича Хетагурова. 2013. № 4. С. 482-486.

3. Тадтаева В.В., Тадтаева Н.В., Цакоев А.Э, Государственный кредит и государственный долг Российской Федерации // Экономика и управление: проблемы, решения. 2017. Т. 6. № 12. С. 129-138.

4. Тадтаева В.В., Касаев К.Р. Устойчивость государственного долга / В сборнике: Молодежь и наука: актуальные вопросы социально-экономического развития развития регионов России Межвузовская научнопрактическая конференция. 2015. С. 76-80.

5. Токаев Н.Х., Сугарова И.В. Размерность бюджетных параметров и сбалансированность бюджетных решений в регионе//Аудит и финансовый анализ. 2015. № 6. С. 267-270. 